\title{
Political Party Perception and Voting Behavior of People: A Study of Communication Perspective from Nepal
}

\author{
Udaya Raj Paudel ${ }^{*}$, Rajesh Gupta ${ }^{2}$, Sameen Poudel ${ }^{3}$, Kabita Adhikari ${ }^{4}$ \\ ${ }^{1}$ Humanities and Social Sciences-English, Tribhuvan University, Kathmandu, Nepal \\ ${ }^{2}$ Management, Pokhara University, Pokhara, Nepal \\ ${ }^{3}$ Humanities and Social Sciences, Tribhuvan University, Kathmandu, Nepal \\ ${ }^{4}$ Management, Tribhuvan University, Kathmandu, Nepal \\ Email: *udayapaudel7@gmail.com
}

How to cite this paper: Paudel, U. R., Gupta, R., Poudel, S., \& Adhikari, K. (2018). Political Party Perception and Voting Behavior of People: A Study of Communication Perspective from Nepal. $A d$ vances in Literary Study, 6, 179-192.

https://doi.org/10.4236/als.2018.64016

Received: August 31, 2018

Accepted: October 16, 2018

Published: October 20, 2018

Copyright (c) 2018 by authors and Scientific Research Publishing Inc. This work is licensed under the Creative Commons Attribution International License (CC BY 4.0).

http://creativecommons.org/licenses/by/4.0/

\begin{abstract}
Communication, political party perception and voting behavior of the people keep congenial nexus. Grounded on this bond, the main purpose of this study is to analyze the factors that impact political party perception and voting behavior of the people in Nepal from the perspective of communication, particularly residing on social networking sites: Facebook, Twitter and YouTube. In purposive sampling method perception level detailed data were obtained from 333 respondents aged 20 years and above just before the historic constitutional assembly election in Nepal. A set of questionnaires including multiple choices and Likert scale questions were provided to obtain the information. Drawing the coherent substance from Technological Determinism, Social Judgment, Agenda Setting, Uses and Gratification, and Habermas's Concept of Public Sphere and Political Campaign theories, the research explores the roles of social media in political party perception and voting behavior. The results show that political interest is positively related to political party perception and voting behavior, which infer that political party perception is influenced by political interest of the politician. The analysis also indicates that political trust is also positively related to political perception and voting behavior, which shows that political trust highly influences political party perception. Likewise, religion and social media are also positively related to political party perception and voting behavior. The study roots on primary source of data and contributes to understand the impact of social media in the society and politics.
\end{abstract}

\section{Keywords}

Communication, Political Party Perception (PPP), Voting Behavior and Social 
Networking

\section{Contextual and Conceptual Background of the Study}

Social media like Facebook, twitter and YouTube have undoubtedly changed the culture of political campaigns by creating virtual communities in which people can engage and share information. The intelligent use of social media networks by political candidates can substantially increase their public relation, thus, allowing a great advantage in the electoral forum! In democratic countries, political parties feel responsible to canalize and participate in public political discussion; however, the traditional structure of mass communication in the political context has changed (Chadwick, 2006). Based on the rapid development of Web 2.0 technologies, it has been argued that the diffusion of the usage of social media as well as other factors (e.g., discussion culture, average age, etc.) have a strong impact on the relevance of public internet based discourses within the political landscape in specific countries (Howard, 2006; Papacharissi, 2002; Tewksbury, 2006).

According to Boeckman \& Tyler (2002) the underlying factor of interpersonal trust functions as an activator towards political opinion and voting behavior. Trust declining has been extensively investigated in literature (Bélanger \& Nadeau, 2005) and most studies tend to use trust as an independent variable to explain political actions such as voting, campaign involvement, and the like (Anderson, 2010). Similarly, Aarts \& Thomassen (2008) also presented the effects of multiple high impact changes on political voting behavior. Recently, though reports vary on different sources, more than 1200 million people worldwide are members of the Facebook network while Twitter counts more than 800 million users in total. Already, U.S. politicians are said to have a leading role in this regard with the most prominent example of Barack Obama, (Hillary Clinton and Donald Trump) being able to successfully employ social media within his last election campaign (Wattal et al., 2010).

However, studies also have shown that a majority of German politicians do not support political communication by social media (e.g., Beckedahl et al., 2008; Christmann et al., 2010). Yet, there is a lack of academic research investigating the reasons for this reluctance of politicians as well as the problems politicians might face to contact (mostly young) voters via the Internet. The growing relevance of the Internet or, more generally, new information and communication technologies (ICT) regarding political issues has been analyzed and documented by researchers since the 1990s (Davis \& Owen, 1998; Davis, 1999; Römmele, 2003; Chadwick, 2006). Originating mostly from the disciplines of political science, communication and sociology, studies for example focus on the impact of internet access on voting (Tolbert \& McNeal, 2003), the use of websites to reach voters (Jansen, 2004; Foot \& Schneider, 2006), the role of the in- 
ternet as a medium for political communication during election campaigns (Stieglitz \& Dang-Xuan, 2012a; Kilinenberg \& Perrin, 2000), visions of digital democracy and the role of new media (Howard, 2006; Papacharissi, 2002; Tewksbury, 2006).

In general, literature communicates different understandings on the function of the Internet in politics. On the one hand, according to the democratization thesis, the Internet's interactive potential is seen as transformational (Barber, 1998). On the other hand, proponents of the normalization thesis of the institutional adaptation thesis foresee no Internet induced change in the fundamental political inequalities of the present system (Margolis \& Resnick, 2000, Chadwick, 2006). Further, Bimber and Davis (2003) argue that the role of the Internet is supplemental rather than to displace traditional media. The rise of Web 2.0 technologies has further increased the relevance of the Internet for political communication. The potentials of social networking sites, blogs, microblogging (in particular, Twitter), wikis, as social software (as cited in Stieglitz, Stefan; Brockmann \& Xuan, Linh Dang, 2012) appear to be most promising in political context as social software can be an enabler for more participation and democracy. Relating to this, Karpf (2009) introduced the notion of "Politics 2.0" and it can be comprehended as the yoking of the internet's lowered transaction costs and its situation of information abundance, toward the goal of building more participatory, interactive political institutions.

Different writers examine the use of Twitter by U.S. Congress members and finds that Congress members are primarily using Twitter to disperse information, particularly links to news articles about themselves and to their blog posts, and to report on their daily activities-Twitter is rather seen as vehicles for self-promotion and facilitating direct communication between Congress members and citizens (Ammann, 2010; as cited in Stieglitz, Stefan \& Xuan, Linh Dang, 2012). Similarly, the role of video sharing platforms such as YouTube in elections has some benefits as well as challenges. Agenda-setting describes a phenomenon which had long been noticed and studied in the context of election campaign, the core is the news media indicate to the public what the main issues of the day are and this is reflected in what the public perceives as the main issues (McCombs \& Shaw, 1972; McCombs \& Shaw, 1993). Thus we can understand that the writers distinguish clearly between three different agenda; the priorities of the media, those of the public, and those of policy, which interact in complex ways and may have effects in different directions.

The mass media communicate political perceptions and codetermines voting behavior (Campus, Pasquino, \& Vaccari, 2008; Pabjan \& Pekalski, 2008; Schmitt-Beck \& Mackenrodt, 2010). Multiple election studies documented the significance of the media in political campaigning by claiming agenda-setting theory effects (Campus, 2008; Dunn, 2009; Balmas \& Sheafer, 2010; Nesbitt-Larking, 2010). The social media has become a powerful medium, which may affect voting behavior because of its potential to provide direct and cheap 
access to the production and consumption of current information at any part of the world without editorial filtering. However, the drawback of this media centered democracy is the lack of face-to-face interaction, and the increased funding to television ads. While Internet is cheaper to advertising medium, TV is still the surest way to reach people (Lilleker, 2006). The new media technologies have arguably enhanced the communication process in a wide range of human endeavors and the political environment no doubt is experiencing a great deal of the impact of new media phenomenon (Nwabueze \& Ezebuenyi, 2012).

The media are indispensable social services that lubricate the engine room of democracy (Linh Dang, 2012). The emphasis is placed on the setting of ever lasting connection between political parties and people. Social media practice is one of several forms of political communication and needs to be examined from the point of view of "social engineering". In this age of paradigm shift, new media practices are required to focus the attention of the people on electioneering process with special reference to Parliament Elections in Nepal.

In the context of Nepal, the emergence of social media began in the early days of Internet. But, in the early days, the number of people using these platforms was limited. (Pye, 1966) opines that new media have robust and unlimited possibilities. Social media platforms, such as Facebook, Twitter, and YouTube provide new ways to encourage citizen engagement in political life, where elections and electoral campaigns ensure a crucial role. Personal Communication via social media conveys politicians and parties closer to their potential voters... allows politicians to communicate faster and reach citizens in a more targeted manner and vice versa. (Stieglitz, Stefan; Brockmann, \& Xuan, 2012; Dunn, 2009 and Shaw, 1972). Communicating politically, Nepal was ruled by autocratic $R a-$ na regime until 1959AD. After Rana regime parties less Panchayat system remained prevalent until 1980 when multiparty democracy heralded with new dream of hope and freedom, and 1989 faced a people's revolution and constitutional monarchy was the political system until 2006 AD but in between 1996 onwards Maoist insurgency began and 2001 remained more traumatic due to royal massacre. The Himalayan Kingdom of south Asia, Nepal, became a Federal Democratic Republic of Nepal on May 8, 2008 by declaring her as State and end of two hundreds and forty years of monarchy ruling system. The first constituent assembly failed to promulgate the constitution draft and the second constituent assembly passed the constitutional bill from the jumbo parliament created through the emancipatory representations of discriminated, scheduled and minorities included as parliamentary members. Hence, the new constitution of Nepal is considered to be one of the most democratic and people's ones in the whole world. Currently, new election of the federal system with new seven states has been completed and Nepali Congress party is in opposition while the Communist Party Nepal has been ruling the nation with two-third of the majority. This historical milieu has been witnessed by the whole world. United Nations Mission in Nepal (UNMIN) contributed to smoothen the transition. In such 
historical movement of Nepal in a decade, a dozen of governments were changed. And the elections always remained great curiosity not only for the people in Nepal but also to the whole world. The present study is rightly based in this juncture, which measures the voting behavior and perception of the people from the perspective of communication, especially by the use of social media like Facebook, twitter and YouTube.

Thus, all the given studies focus on the roles of social media in elections but do not address the unique and exceptional historical journey of Nepal. In the lack of comprehensive research, the present study tries to explore the effects of social media in determining the perception and voting behavior of people in Nepal. The forthcoming sections of this research paper in sequence are: Theoretical Framework, Materials and Methods, Results and Discussion and Concluding Remarks followed by References.

\section{Theoretical Framework}

Political party perception and voting behavior of the people are affected by a number of variables. And there are a number of theories related to the study, yet, mainly, this study is anchored on the Technological Determinism, Social Judgment, Public Sphere and Political Campaign Concept of Habermas, Agenda Setting and Usage and Gratification Theories.

Technological Determinism Theory, propounded by Marshall McLuhan (1964), a Canadian communication scholar, observed the roles of new media technologies in communication in determining social changes, turning the world into a global village. He believes socio-political, economic and cultural changes are inevitably based on development and diffusion of technology. The theory states that communication technologies in general are the prime causes of changes in society. Technological determinism is the thinking in some quarters that it is machine and their developments drive historical, economic, political and cultural changes. There is, however, a perspective to technological determinism, which sees technology as more neutral and claims the way people use it is what gives it significance.

Social Judgment Theory suggests that exposure to political campaigns encourages people to "assimilate" or equate their feelings about related target attitudes. The theory is of the view that voters as rational stakeholders should make necessary judgment on how to perceive or react to these messages depending on how it conforms to their pre-existing attitudes on their expectations from politics. Social media messages targeted at ensuring democracy, eradicating poverty, providing of employment and guaranteeing security which are the basic expectations of the youths in the present. Likewise messages emphasizing some lapses of the government in power may trigger negative reactions from the electorate.

Similarly, Habermas focuses on democratization linked with emphasis on political participation as the core of a democratic society and as an essential element in individual self-development. The Facebook political campaign allows for liberal democracy where everybody says what he or she feels. The public 
sphere thus presupposes freedom of speech, press and the right to freely participate in political activities and decision-making. For Habermas, the function of the media has thus been transformed from facilitating rational discourse and debate within the public sphere into shaping, constructing, and limiting public discourse to those themes validated and approved by media corporations. Political public spheres include social movements, media that monitor and criticize the state, and groups that take political action. Facebook has become contested terrain, a new form of a class struggle, national liberation, and pro-democracy movements.

Since Agenda Setting Theory examines the role of Facebook in political movements as well as the inventiveness of Facebook posts on electorate voting choice of a particular candidate, it is pertinent to back up this paper with the agenda-setting theory of the media. Agenda setting depicts an intense impact of the media; the capacities to disclose to us what issues are noteworthy. This implies that the media is geared towards influencing people's perception of what is necessary, acceptable and desirable. During elections, politicians and electorate to propagate their views and opinions use different media. Candidates post different messages on social media and such messages over time create agenda. Thus, it is also witnessed that social media utilization shaped, influenced and set agenda for people in southern Taraba in the 2015 Nigeria senatorial elections.

Katz, Blumler and Gurevitch propounded the Uses and Gratification Theory in 1974 (Wimmer \& Dominick, 2011: p. 294). It directly places power in the hands of the audience. Linking this theory to the present study, politicians use social media most particularly Facebook to influence the electorate to vote for them. Social media platforms are without doubt a notable tool today that promotes the participation of citizens of a country, nation or states in politics and other civic activities.

\section{Study Methods}

The study is based on primary data collected through the questionnaires seeking information on both dependent and independent variables using Likert scale and other questions. The study used simple random sampling for survey, where it sampled 333 respondents including students, professors, politicians, doctors, engineers. The respondents were between 20 to 65 years old. Both descriptive and inferential statistics are performed for data analysis. The descriptive design has been adopted for finding the required fact, and the causal comparative research design for identifying the cause and effect relationship between dependent and independent variables. The reliability and validity results show that the instrument was both reliable and valid with Cronbach's alpha of 0.833 . It means that the data were 83.3 percent of the data taken for the study are reliable and remaining 16.7 percent is error

\section{Model Specification}

Kaiser-Meyer-Olkin (KMO), The Communalities Measure, Eigen Value Test, 
One Sample Test and Regression analysis have been exploited along with descriptive statistics; (frequency and percentage and reliability analysis techniques are used) to test the hypothesized relationship between the dependent and the independent variables.

$$
\mathrm{Y}=\beta_{0}+\beta_{1} \mathrm{PI}+\beta_{2} \mathrm{PT}+\beta_{3} \mathrm{REG}+\beta_{4} \mathrm{SM}+e
$$

where, $\mathrm{Y}=$ Political Party Perception

$$
\begin{aligned}
& \mathrm{B}=\text { Constant Variable } \\
& \mathrm{PI}=\text { Political Interest } \\
& \mathrm{PT}=\text { Political Trust } \\
& \mathrm{REG}=\text { Religion } \\
& \mathrm{SM}=\text { Social Media } \\
& e=\text { Error }
\end{aligned}
$$

$\beta_{1}, \beta_{2}, \beta_{3}, \beta_{4}$ are regression coefficient that refer to the amount with which a dependent variable increases when one of these independent variable increases while other remain constant.

\section{Results and Discussion}

The data and information collected from the respondents are presented, interpreted and analyzed. The questionnaire was presented in the purposive manner to obtain the data. The data was entered in SPSS for further analysis. Frequency table, cross tabulation, correlation and reliability analysis are presented and interpreted.

\subsection{Descriptive Analysis}

Based on the analysis of data, the major findings of the study are summarized in Table 1. Among the 333 respondents, (57\%) of the respondents were males and (43\%) females. From the sample size (28\%) of the respondents were between 20 to 30 years age groups, (35\%) between $30-40$, (28\%) were in $40-50$ and only (9\%) of the respondents were above 50 years. In terms of education background, only (2\%) of the respondents were $\mathrm{PhD},(7 \%)$ were intermediate level passed whereas, $(48 \%)$ and (43\%) of the respondents were bachelor and master's levels educated respectively. Again, $(8 \%)$ of the respondents were doctors, (12\%) were engineers and businesspersons each. (17\%) were professors, $(22.1 \%)$ and (33.6\%) were politicians and students respectively. Out of total 333 respondents, (68\%) of the respondents believed that politicians are used to using Facebook twitter and YouTube as they have gone through their uploads in the internet. In Table 1, out of total 333 respondents, (8\%) of the respondents were doctors, (11.5\%) and were equally engineers and businesspersons. (17\%) are professors, $(22 \%)$ and (34\%) were politicians and students respectively. The social networking sites are categorized into Facebook, twitter, and YouTube. (66\%) of the respondents believed that politicians use Facebook, (20\%) of the respondents believed they use twitter and (12\%) of the respondents responded that politicians use YouTube. In terms of the respondents' awareness and exposure to social media of the 
Table 1. Descriptive analysis of the variables.

\begin{tabular}{|c|c|c|}
\hline Variables & Category & Percent \\
\hline \multirow[t]{4}{*}{ Gender of respondents } & Male & 57 \\
\hline & Female & 43 \\
\hline & $20-30$ & 28 \\
\hline & $30-40$ & 35 \\
\hline \multirow[t]{2}{*}{ Age of respondent } & $40-50$ & 28 \\
\hline & $>50$ & 9 \\
\hline \multirow[t]{4}{*}{ Qualification of respondents } & Intermediate & 7 \\
\hline & Bachelor & 48 \\
\hline & Master & 43 \\
\hline & $\mathrm{PhD}$ & 2 \\
\hline \multirow[t]{4}{*}{ Occupation of respondents } & Doctors & 8 \\
\hline & Engineer and Business Person & 12 \\
\hline & Professors & 17 \\
\hline & Politicians and Student & 33.6 \\
\hline \multirow[t]{3}{*}{ Social networking sites } & Facebook & 68 \\
\hline & Twitter & 20 \\
\hline & YouTube & 12 \\
\hline \multirow{2}{*}{$\begin{array}{l}\text { Awareness and exposure to social media } \\
\text { of the respondents }\end{array}$} & Agree & 57 \\
\hline & Disagree & 43 \\
\hline
\end{tabular}

respondents. Majorities (57\%) of the respondents agreed with the statement followed by (43\%) of the respondents disagreed.

In the case of impediments against illustrated in Table 2, the use of social media as political platform in Nepal, out of total 333 respondents, majorities (35\%) of the respondents see that impediments against the use of social media is due to lack of internet access, (22\%) due to low ICT literacy, (18\%) see that it is due to lack of credibility on the web, (20\%) due to lack of constant electricity supply and $(5 \%)$ believe it is due to poverty. In the statement: PPP is based on party confidence, party intelligence, progressiveness, vision and reputation, out of total 333 respondents, majorities (46\%) of the respondents strongly agree with the statement, followed by (40\%) of the respondents agree, and the remaining (14\%) of the respondents are neutral with the statement. Among the respondents, $(18 \%)$ of the respondents strongly agreed with the statement-voting behavior is construction of voting intention and factors constructing voting behavior, followed by (43\%) of the respondents "agree", (33\%) neutral where as, only (3\%) and $(2 \%)$ of the respondents disagree and strongly disagree respectively. Similarly, (51\%) of the respondents disagreed with the statement-political website and blogs mobilize inactive citizen. Following that (33\%) of respondents strongly disagree and $(15 \%)$ of the respondents expressed neutral view towards the 
Table 2. Descriptive analysis of the variables.

\begin{tabular}{|c|c|c|}
\hline Variables & Determinants & Percent \\
\hline \multirow{4}{*}{$\begin{array}{l}\text { Impediments against the use of social media is } \\
\text { due to lack of }\end{array}$} & Internet access & 35 \\
\hline & Low ICT literacy & 22 \\
\hline & Lack of credibility on the web & 18 \\
\hline & Lack of electricity supply & 20 \\
\hline \multirow{3}{*}{$\begin{array}{l}\text { PPP is based on party confidence, party intelligence, } \\
\text { progressiveness, vision and reputation }\end{array}$} & Strongly Agree & 46 \\
\hline & Agree & 40 \\
\hline & Neutral & 14 \\
\hline \multirow{5}{*}{$\begin{array}{l}\text { Voting behavior is constructed of voting intention } \\
\text { and factors constructing voting behavior }\end{array}$} & Strongly Agree & 18 \\
\hline & Agree & 43 \\
\hline & Neutral & 33 \\
\hline & Disagree & 3 \\
\hline & Strongly Agree & 2 \\
\hline \multirow[t]{3}{*}{ Do political website and blogs mobilize inactive citizen? } & Neutral & 15 \\
\hline & Disagree & 51 \\
\hline & Strongly Disagree & 33 \\
\hline \multirow[t]{2}{*}{ Do social media enhance political party perception. } & Agree & 53 \\
\hline & Neutral & 45 \\
\hline
\end{tabular}

statement. Again, (53\%) of the respondents agreed that social media enhance political party perception whereas (45\%) of the respondents remained neutral.

\subsection{Inferential Analysis}

In inferential analysis the following tests were conducted to find out the results: Kaiser-Meyer-Olkin (KMO), The Communalities Measure, Eigen Value Test, One Sample Test and Regression Analysis.

Kaiser-Meyer-Olkin (KMO) measures the sampling adequacy and Bartletts method tests of sphericity. The KMO statistic varies between 0 and 1 . The value of 0 indicates that the sum of partial correlations is largely relative to the sum of correlations, indicating diffusion in the pattern of correlations (hence, factor analysis is likely to be inappropriate). A value close to 1 indicates that pattern of correlations are relatively compact and so factor analysis should yield distinct and reliable factors. Kaiser (1974) asserts accepting values greater than 0.5 as acceptable. Besides, values between 0.5 and 0.7 are mediocre, values between 0.7 and 0.8 are good, values between 0.8 and 0.9 are important and values above 0.9 are very significant (Hutcheson \& Sofroniou, 1999). From the tests in Table 3, the KMO value is 0.843 , which falls into the range of being good, hence factor analysis is appropriate for the data. Similarly, Bartlett's also measure analyses the null hypothesis that the original correlation matrix is an identity matrix, hence, it tells that the test in this research is not only significant but also implies that 
the variables possess some correlation to each other, therefore, factor analysis is also appropriate in the study.

The Communalities measure has been exploited in the data before and after extraction in Table 4. Primary component analysis purposes on the initial assumption that all variance remained common; therefore, before extraction the communalities are all 1. The communalities in the labeled extraction reflected the common variance in the data structure. In presenting the facts, over $94 \%$ of the variance in political trust is accounted while only $44.5 \%$ of variance in religion is accounted.

In the explanation of total variance, eigenvalue is associated with each linear component (factor) before and after extraction. The eigenvalues associate with each factor represent the variance explained by that particular linear component and the output displays the eigenvalue in terms of the percentage of variance explained in Table 5. Factor 1 explained $29.519 \%$ of total variance. In the final part of Labeled Rotation Sums of Squared Loadings, the eigenvalues of the factors after rotation were abstracted. Rotation had the effect of optimizing the factors

Table 3. Analysis of KMO and Bartlett's test.

\begin{tabular}{ccc}
\hline \multicolumn{2}{c}{ KMO and Bartlett's Test } & \\
\hline Kaiser-Meyer-Olkin Measure of Sampling Adequacy. & 0.843 \\
Bartlett's Test of Sphericity & Approx. Chi-Square & 65.441 \\
& df & 10 \\
\hline
\end{tabular}

Table 4. Analysis of communalities test.

\begin{tabular}{ccc}
\hline & \multicolumn{2}{c}{ Communalities } \\
Initial & Extraction \\
\hline PPPVB & 1.000 & 0.672 \\
PI & 1.000 & 0.763 \\
PT & 1.000 & 0.940 \\
REG & 1.000 & 0.445 \\
SM & 1.000 & 0.785 \\
\hline
\end{tabular}

Extraction Method: Principal Component Analysis.

Table 5. Analysis of total variance.

\begin{tabular}{|c|c|c|c|c|c|c|c|c|c|}
\hline \multicolumn{10}{|c|}{ Total Variance Explained } \\
\hline \multirow{2}{*}{ Component } & \multicolumn{3}{|c|}{ Initial Eigenvalues } & \multicolumn{3}{|c|}{ Extraction Sums of Squared Loadings } & \multicolumn{3}{|c|}{ Rotation Sums of Squared Loadings } \\
\hline & Total & $\%$ of Variance & Cumulative\% & Total & $\%$ of Variance & Cumulative\% & Total & $\%$ of Variance & Cumulative\% \\
\hline 1 & 1.476 & 29.519 & 29.519 & 1.476 & 29.519 & 29.519 & 1.341 & 26.818 & 26.818 \\
\hline 2 & 1.172 & 23.448 & 52.967 & 1.172 & 23.448 & 52.967 & 1.241 & 24.815 & 51.632 \\
\hline 3 & 0.957 & 19.141 & 72.108 & 0.957 & 19.141 & 72.108 & 1.024 & 20.475 & 72.108 \\
\hline 4 & 0.880 & 17.598 & 89.706 & & & & & & \\
\hline 5 & 0.515 & 10.294 & 100.000 & & & & & & \\
\hline
\end{tabular}

Extraction Method: Principal Component Analysis. 
was equalized. Before rotation, factor 1 accounted for considerably more variance that the remaining two (29.519\% compared to $23.448 \%$, and $19.141 \%$ ), however after extraction it accounts, reduced to $26.818 \%$ of variance (compared to $24.815 \%$, and 20.475 ).

In order to test the hypothesis, one sample t-test and regression analysis have been explained in Table 6. All the variables that have been used for the study are significant because the probability value is less than (5\%). So, the variables used are significant. Among all the independent variables, the p-value of political interest, political trust, religion, and social media are less than 5\% i.e. 0.05 . And for these dependent variables, the t-value for B (coefficient) was significant and implies that this variable is a significant predictor. Based on the coefficient output, collinearity statistic, obtain VIF values for all the independent variable is less than 5 , which implies that there is no multicollinearity symptoms between the independent variables. The value of 0.471 in Dubin-Watson test implies that there is autocorrelation between the variables. The regression results are based on weighted mean value of perceived Likert value by using linear regression model. The model is:

$\mathrm{R}$ square as 0.871 , which are high and explain that $87.1 \%$ of the variation in political party perception and voting behavior is explained by the variation in the independent predictors. In the hypothesis testing, political interest, political trust, religion and social media in relation to political party perception and voting behavior resulted with the P-value $0.000,0.032,0.017$ and 0.004 respectively and thus, all remained accepted.

\section{Concluding Remarks}

A PCA with subsequent rotation (Varimax) was conducted on 5 variables of the questionnaire based on political party perception and voting behavior and the factors affecting them. Out of 5 factors, only one factor has correlations in excess of 0.30 and both the KMO and Bartlett's tests produced criteria that support the application of PCA. Communalities varied from 0.94 to 0.445. Applying Kaiser's Rule and the Scree test, two factors were deemed important. In short, this study of political party perception and voting behavior of Nepali people depicts that

Table 6. Regression analysis.

\begin{tabular}{ccccccccc}
\hline Variable & B & T & Sig & $\begin{array}{c}\text { Collinearity } \\
\text { Statistics VIF }\end{array}$ & F & Sig & $\mathrm{R}^{2}$ & DW \\
\hline (Constant) & 0.969 & 2.341 & 0.020 & & & & & \\
PI & 0.460 & 6.029 & 0.000 & 1.079 & & & & \\
PT & -0.070 & -0.991 & 0.032 & 1.020 & 12.029 & 0.000 & 0.871 & 0.471 \\
REG & -0.181 & -2.412 & 0.017 & 1.012 & & & & \\
SM & 0.210 & 2.872 & 0.004 & 1.087 & & & & \\
\hline
\end{tabular}

Note: Dependent Variable (Political Part Perception), Predictors: PI (Political Interest), PT (Political Trust), REG (Religion), and SM (Social Media). 
political interest is positively related to political party perception and voting behavior, which implies that political party perception are influenced by political interest of the politician. Similarly, political trust is also positively related to political perception and voting behavior. The highest correlation has been observed to be political party perception/voting behavior and political interest whereas lowest is observed between political trust and religions. The entire coefficients have positive relation with each other. Thus it can be safely concluded that political trust highly influences political party perception. Likewise, religion and social media are also positively related to political party perception and voting behavior.

\section{Conflicts of Interest}

The authors declare no conflicts of interest regarding the publication of this paper.

\section{References}

Anderson, M. R. (2010). Community Psychology, Political Efficacy and Trust. Political Psychology, 31, 59-84. https://doi.org/10.1111/j.1467-9221.2009.00734.x

Balmas, M., \& Sheafer, T. (2010) Candidate Image in Electiion CAMPAIGNS: Attribute Agenda Setting, Affective Priming, and Voting Intentions. International Journal of Public Opinion Research, 22, 204-229. https://doi.org/10.1093/ijpor/edq009

Barber, B. (1998). Three Scenarios for the Future of Technology and Strong Democracy. Political Science Quarterly, 113, 573-589. https://doi.org/10.2307/2658245

Beckedahl, M., Lüke, F., \& Hirsch, S. (2008). Politik in Web 2.0. http://www.newthinking.de/

Bélanger, É., \& Nadeau, R. (2005). Political Trust and the Vote in Multiparty Elections: The Canadian Case. European Journal of Political Research, No. 44, 121-146. https://doi.org/10.1111/j.1475-6765.2005.00221.x

Bimber, B., \& Davis, R. J. (2003). Campaigning Online: The Internet in U.S. Elections. NY: Oxford University Press.

Boeckman, R., \& Tyler, T. R. (2002). Trust, Respect, and the Psychology of Political Engagement. Journal of Applied Social Psychology, 32, 2067-2088. https://doi.org/10.1111/j.1559-1816.2002.tb02064.x

Campus, D., Pasquino, G., \& Vaccari, C. (2008). Social Networks, Political Discussion, and Voting in Italy: A Study of the 2006 Election. Political Communication, 25, 423-444. https://doi.org/10.1080/10584600802427039

Chadwick, A. (2006). Internet Politics: States, Citizens, and New Communications Technologies. New York: Oxford University Press.

Christmann, S., Melcher, J., Hagenhoff, S., Stock Gissendanner, S., \& Krumbein, W. (2010). In Web 2.0-Technologien in politischen Meinungsbildungsprozessen von Parteien: Ein Beispiel aus der Praxis (Fähnrich, K.-P. and Franczyk, B. Eds.), 687-698, INFORMATIK 2010 - Service Science - Neue Perspektiven für die Informatik, Band 1, Leizpig, Germany.

Davis, R. (1999). The Web of Politics: The Internet's Impact on the American Political System. New York: Oxford University Press.

Davis, R., \& Owen, D. (1998). New Media and American Politics. New York: Oxford 
University Press.

Dunn, S. W. (2009). Candidate and Media Agenda Setting in the 2005 Virginia Gubernatorial Election. Journal of Communication, No. 59, 635-652. https://doi.org/10.1111/j.1460-2466.2009.01442.x

Foot, K. A., \& Schneider, S. M. (2006). Web Campaigning. Cambridge. MA: MIT Press.

Howard, P. N. (2006). New Media Campaigns and the Managed Citizen. New York, NY: Cambridge University Press.

Hutcheson, G., \& Sofroniou, N. (1999). The Multivariate Social Scientist. London: Sage. https://doi.org/10.4135/9780857028075

Jansen, H. (2004). Is the Internet Politics as Usual or Democracy's Future? Candidate Campaigns Web Sites in the 2001 Alberta and British Columbia Provincial Elections. The Innovation Journal: The Public Sector Innovation Journal, 9, 1-20.

Karpf, D. (2009). Blogosphere Research: A Mixed-Methods Approach to Rapidly Changing Systems. IEEE Intelligent Systems, 24, 67-70.

Kilinenberg, E., \& Perrin, A. (2000). Symbolic Politics in the Information Age: The 1996 Republican Presidential Campaigns in Cyberspace. Information, Communication \& Society, 3, 17-38. https://doi.org/10.1080/136911800359400

Lilleker, D. G. (2006). Key Concepts in Political Communication. London: Sage.

Margolis, M., \& Resnick, D. (2000). Politics as Usual: The Cyberspace "Revolution". Thousand Oaks, CA: Sage Publications.

McCombs, M. E., \& Shaw, D. L. (1972). The Agenda-Setting Function of Mass Media. Public Opinion Quarterly, 36, 176-187. https://doi.org/10.1086/267990

Nesbitt-Larking, P. W. (2010). The Role of the Media in Electoral Behavior: A Canadian Perspective. Policy and Society, 29, 53-64. https://doi.org/10.1016/j.polsoc.2009.11.005

Nwabueze, C. D., \& Ezebuenyi, E. E. (2012). Appraising the Relevance of ICTs in Awareness Creation during Election. Journal of Linguistics and Communication Studies, 2, 293-302.

Pabjan, B., \& Pekalski, A. (2008). Model of Opinion Forming and Voting. Physica A: Statistical Mechanics and Its Applications, 387, 6183-6189.

https://doi.org/10.1016/j.physa.2008.07.003

Papacharissi, Z. (2002). The Virtual Sphere: The Internet as a Public Sphere. New Media and Society, 4, 9-27. https://doi.org/10.1177/14614440222226244

Pye, L. W. (1966). Aspects of Political Development. New Delhi: Ameren Publishing Co.

Römmele, A. (2003). Political Parties, Party Communication and New Information and Communication Technologies. Party Politics, 9, 7-20. https://doi.org/10.1177/135406880391002

Schmitt-Beck, R., \& Mackenrodt, C. (2010). Social Networks and Mass Media as Mobilizers and Demobilizers: A Study of Turnout at a German Local Election. Electoral Studies, 29, 392-404. https://doi.org/10.1016/j.electstud.2010.03.011

Stieglitz, S., \& Linh, D.-X. (2012a). Political Communication and Influence through Microblogging-An Empirical Analysis of Sentiment in Twitter Messages and Retweet Behavior. In Proceedings of the 45th Hawaii International Conference on System Sciences (pp. 3500-3509). Piscataway, NJ: Institute of Electrical and Electronics Engineers.

Tewksbury, D. (2006). Exposure to the New Media in a Presidential Primary Campaign. Political Communication, 23, 313-332. https://doi.org/10.1080/10584600600808877

Tolbert, C. J., \& McNeal, R. S. (2003). Unraveling the Effects of the Internet on Political 
Participation. Political Research Quarterly, 56, 175-185.

https://doi.org/10.1177/106591290305600206

Wattal, S., Schuff, D., Mandviwalla, M., \& Williams, C. (2010). Web 2.0 and Politics: The 2008 U.S. Presidential Election and an E-Politics Research Agenda. MIS Quarterly, 34, 669-688.

Wimmer and Dominik (2011). Mass Media Research: An Introduction. New Delhi: Engage Learning India Pvt. Ltd. 